\title{
A Luta por Reconhecimento: base para uma educação voltada à construção da cidadania?
}

\author{
The Struggle for Recognition: \\ basis for an education \\ for citizenship building?
}

\section{Resumo}

Este artigo tem por objetivo indagar se e como o instrumental teórico apresentado por Axel Honneth em Luta por reconhecimento: a gramática dos conflitos sociais pode contribuir para aprimorar o processo educacional orientado à construção da cidadania. Essa indagação visa evidenciar locus privilegiado para o ensino de filosofia, em particular, no nível médio, voltado ao reforço de valores e referências para a vida em sociedade que orientem os educandos na busca de autorrealização pessoal como cidadãos. No ensino médio, sugere-se a adoção de práticas pedagógicas que remetam ao aprendizado das três etapas de reconhecimento identificadas por Honneth (o amor, o direito e a solidariedade) e ao desenvolvimento de seus correspondentes reflexos nas relações sociais, quais sejam a autoconfiança, o autorrespeito e a autoestima.

Palavras-chave: filosofia; educação; pedagogia social; reconhecimento; cidadania.

*Universidade de Brasília (UnB); Doutor em Filosofia pelaUERJ. E-mail: rainri.back@yahoo.com.br

** Mestre em Metafísica na Universidade de Brasília (UnB).E-mail: everton_lucero@yahoo.com.br

Recebido em: 14/02/2019 Aceito em: 16/07/2019 


\begin{abstract}
This article aims to investigate if and how the theoretical instruments presented by Axel Honneth in Struggle for Recognition: the grammar of social conflicts may contribute to improve the educational process oriented to the construction of citizenship. This question highlights a privileged locus for teaching philosophy, particularly at the middle level, aimed at reinforcing values and references to life in society that guide students in the search for personal self-realization as citizens. At the regular education, it is suggested the adoption of pedagogical practices related to the learning of the three stages of recognition identified by Honneth (love, law and solidarity) and the development of their corresponding counterparts in social relations, such as self-confidence, self-respect and self-esteem.
\end{abstract}

Keywords: Philosophy. Education. Social Pedagogy. Recognition. Citizenship.

Este artigo pretende responder às seguintes indagações: seria a teoria da luta por reconhecimento, de Axel Honneth, relevante no sentido de embasar uma pedagogia social voltada para a educação cidadã? Em caso afirmativo, poderia essa mesma teoria orientar o ensino de filosofia no ensino médio, em linha com o que dispõe a Base Nacional Comum Curricular?

Para responder a essas indagações, serão apresentados, numa primeira parte, os três níveis de reconhecimento de que trata Honneth, que se situam nas searas do amor, do direito e da solidariedade. Será indicado, ainda, como Honneth entende que se dá a quebra ou a violação do reconhecimento em cada um desses níveis e quais as respectivas consequências nas esferas subjetiva e interpessoal. Em cada nível, buscar-se-á estabelecer relações entre a luta por reconhecimento e o ambiente educacional, no intuito de evidenciar o potencial daquela teoria para aprimorar o processo educativo, com ênfase na formação cidadã, em particular, no ensino médio. Uma vez estabelecidas essas relações e fundamentada a pertinência da teoria da luta por reconhecimento para uma pedagogia social voltada à formação da cidadania, buscar-se-á analisar, na segunda parte, as contribuições que essa teoria pode trazer para aprimorar o ensino de filosofia no nível médio, sem descuidar do necessário alinhamento com a Base Nacional Comum Curricular. Essa análise buscará fundamentar a práxis pedagógica em filosofia, tendo por referência a ampliação das relações de reconhecimento. 
A motivação desse estudo é buscar evidenciar o importante papel que o ensino de filosofia pode desempenhar no processo educacional. Com apoio na análise apresentada, pretende-se contribuir para uma melhor compreensão do potencial que o ensino da filosofia tem para a superação de conflitos interpessoais que comumente se manifestam no contexto educacional e que, por não serem adequadamente tratados, tendem a trasladar-se e reproduzir-se na vida social. Pretende-se evidenciar, enfim, a necessidade de promover uma pedagogia de vertente social que fortaleça o desenvolvimento do potencial criativo e da originalidade no ensino de filosofia, em particular, no ensino médio.

O trabalho insere-se em área tangente à filosofia social e à filosofia da educação e toma como base teórica a obra Luta por reconhecimento: a gramática dos conflitos sociais, de Axel Honneth ${ }^{1}$. O autor é representante contemporâneo da Teoria Crítica surgida na Escola de Frankfurt e atualizada por Jürgen Habermas. Sua teoria fundamenta-se filosoficamente na interpessoalidade, conforme teorizada pelo jovem Hegel, em seus escritos de Jena.

\section{A gramática dos conflitos sociais aplicada à realidade educacional}

A teoria da luta por reconhecimento de Axel Honneth tem origem filosófica no Iluminismo e relaciona-se àquela do princípio de autonomia do ser humano. ${ }^{2} \mathrm{O}$ fundamento ontológico que se pode tomar como ponto de partida para a aplicação da gramática dos conflitos sociais à realidade educacional é o postulado hegeliano, segundo leitura de Alexander Kojève, ${ }^{3}$ de que "o homem é consciência de si". No linguajar de Hegel, "a consciência-de-si é em si e para si quando e por que é em si e para si para uma Outra; quer dizer, só é como algo reconhecido". Nessa concepção, a tomada de consciência que origina o aspecto subjetivo não adviria da contemplação nem do conhecimento de si, mas do desejo de reconhecimento. Esse postulado adquire pertinência para embasar uma pedagogia orientada à construção da cidadania, na medida em que se adota uma concepção ampla de educação, que vá além

1 Honneth, A. Luta por Reconhecimento: a gramática dos conflitos sociais. 2. ed. São Paulo: Editora 34, 2009.

2 Flickinger, H. Autonomia e reconhecimento: dois conceitos-chave na formação. Educação, v. 34, n. 1. 2011.

3 Kojève, A. Introdução à Leitura de Hegel. Rio de Janeiro: Contraponto, 2002, p. 11.

4 Hegel, G.W.F. Fenomenologia do Espírito. 2 ed. Petrópolis: Vozes, 2003, p. 142, grifo do autor. 
da transmissão formal de conhecimentos e que possa ser entendida como a experiência pela qual alguém se torna o que é; uma experiência contínua ao longo da existência que só é possível de ocorrer na relação interpessoal, o que pressupõe o reconhecimento recíproco.

Conforme indicou Hans-Georg Flickinger, ${ }^{5}$ a fundamentação ética proposta por Axel Honneth com vistas a um projeto de sociedade solidária e justa, apesar de ter tido grande repercussão nas ciências sociais, tem recepção ainda modesta na práxis pedagógica. A pertinência da aplicabilidade da teoria do reconhecimento proposta por Honneth à seara da pedagogia social encontra amparo na seguinte passagem:

(...) os indivíduos se constituem como pessoas unicamente porque, da perspectiva dos outros que assentem ou encorajam, aprendem a se referir a si mesmos como seres a que cabem determinadas propriedades e capacidades. A extensão dessas propriedades e, por conseguinte, o grau da autorrealização positiva crescem com cada nova forma de reconhecimento, a qual o individuo pode referir a si mesmo como sujeito (...). ${ }^{6}$

Cabe recordar que, para Hegel, ${ }^{7}$ o fundamento de toda ação humana encontra-se no desejo, que motiva o homem a agir para satisfazê-lo, tendo como resultado a destruição ou transformação do objeto desejado e a criação, em seu lugar, de uma realidade subjetiva. Nas palavras de Hegel, "esse processo vai apresentar primeiro o lado da desigualdade de ambas [as consciências-de-si] ou o extravasar do meio-termo nos extremos, os quais, como extremos, são opostos um ao outro; um extremo é só o que é reconhecido [senhor]; o outro, só o que reconhece [escravo]".

De acordo com a leitura que Kojève ${ }^{9}$ faz de Hegel, o desejo humano será sempre plural, no sentido de que cada indivíduo é um desejo que busca os desejos dos outros, o que pressupõe que a experiência humana é necessariamente social. No pensamento hegeliano, a sociedade pode ser descrita como

5 Flickinger, H. A teoria do reconhecimento na práxis pedagógica: a exemplo de conflitos entre diretrizes ético-morais. Revista Espaço Pedagógico, v. 18, n. 2, 24 maio 2012. p. 10.

6 HONNETH, Luta por reconhecimento: a gramática dos conflitos sociais, 2009, p. 272, grifo nosso.

7 Hegel, G.W.F., op. cit., p. 140

8 Ibidem, p. 144

9 Kojève, A., op. cit., p. 13. 
o conjunto de desejos desejando-se mutuamente. O "desejo antropogênico" não tem por objeto a matéria, o corpo ou algo do mundo fenomênico, mas sim outro desejo. Nessas condições, o desejo visa à objetificação do outro, o que impõe uma luta de vida ou morte pelo prestígio de tornar-se senhor de si, em detrimento da subjetividade alheia, a qual, para realizar a subjetividade do senhor, deve renunciar à sua subjetividade e aceitar a condição de escravo. Para Hegel, ${ }^{10}$ as figuras do senhor e do escravo "são como duas figuras opostas da consciência: uma, a consciência independente para a qual o ser-para-si é a essência; outra, a consciência dependente para a qual a essência é a vida, ou o ser para um Outro. Uma é o senhor, outra é o escravo". Kojève, ${ }^{11}$ comentando Hegel, afirma que "em seu estado nascente, o homem nunca é apenas homem. É, necessária e essencialmente, senhor ou escravo.".

Honneth elabora os contornos de uma teoria social que se assenta no conflito oriundo da luta por reconhecimento, tal como apresentada por Hegel. O conceito de luta social, que na acepção hegeliana traduz-se num "momento do movimento ético no interior do contexto social da vida", ${ }^{12}$ oferece subsídio para Honneth desenvolver sua teoria, na qual a formação do indivíduo e o desenvolvimento de sua subjetividade estão assentadas na relação social subjacente à luta pelo reconhecimento. Essa luta opera, segundo Honneth, ${ }^{13}$ em três níveis distintos e sucessivos da vida constitutiva do sujeito: (1) o reconhecimento resultante da dedicação emotiva, que se manifesta na relação amorosa entre pais e filhos; (2) o reconhecimento resultante do respeito cognitivo que, por meio da atribuição jurídica de direitos subjetivos, gera a imputabilidade moral do sujeito em sociedade; e (3) o reconhecimento oriundo da estima social, que resulta da solidariedade que se estabelece entre os membros de uma mesma comunidade de valores.

Para Honneth, ${ }^{14}$ quando o sujeito vivencia uma experiência de reconhecimento, adquire um entendimento positivo sobre si mesmo; quando, ao contrário, ele experimenta uma situação de desrespeito, a sua autorrelação positiva, adquirida intersubjetivamente, adoece. Para cada um dos níveis

10 Hegel, G.W.F., op. cit., p. 147.

11 Kojève, A., op. cit., p. 15.

12 Honneth, A., op. cit., p. 48.

13 Ibidem, p. 211.

14 Saavedra, G. A.; Sobotka, E. A. Introdução à teoria do reconhecimento de Axel Honneth. Civitas - Revista de Ciências Sociais, 2008, v. 8, n. 1 (jan.-abr.), p. 14. 
de reconhecimento social, há uma forma correspondente de desrespeito que ameaça a subjetividade individual. O não-reconhecimento no nível das relações primárias de amor e amizade (tipo 1 acima) ameaça a integridade física, por maus-tratos ou violações ao sujeito, o que afeta, em consequência, a sua autoconfiança. O não-reconhecimento dos direitos juridicamente assegurados (tipo 2), que ocorre quando há privação, revogação ou exclusão desses direitos, afeta o autorrespeito e ameaça a integridade social dos sujeitos envolvidos. O não-reconhecimento das capacidades e propriedades individuais adquiridas dentro de uma comunidade de valores compartilhados (tipo 3), por sua vez, ameaça a autoestima, pela via da degradação e da ofensa à honra, ao prestígio e à dignidade dos sujeitos afetados. ${ }^{15}$

Vale lembrar que Hegel $^{16}$ descreve a ação humana como toda a atividade que visa à transformação de um mundo hostil ao projeto humano em um mundo que esteja de acordo com esse projeto. Axel Honneth ${ }^{17}$ sustenta que, para Hegel, o processo histórico de criação das instituições políticas e sociais é um processo que resulta da luta constante dos homens pelo reconhecimento recíproco de sua identidade, com vistas a assegurar o exercício prático da liberdade. Pode-se levantar, aqui, a questão se a escola funcionaria, nas condições apontadas por Honneth, como um possível "microcosmo" do processo de reconhecimento social e afirmação da subjetividade, para o qual confluiriam simultaneamente os três níveis de reconhecimento: o afetivo, o jurídico e o solidário.

Há duas possíveis críticas à aplicabilidade da teoria do reconhecimento de Honneth à realidade educacional. Primeiramente, cabe lembrar que, segundo Honneth, a luta por reconhecimento "evolui" historicamente em direção a relações sociais cada vez mais livres, cada vez mais abertas a novas formas de vida. Poder-se-ia questionar, nesse aspecto, qual seria a função da escola, uma vez que essa evolução aconteceria no contexto das próprias relações sociais, independentemente de qualquer processo formal de aprendizagem. Consideramos que foge ao escopo do presente texto endereçar resposta a essa crítica, por se tratar de uma discussão muito mais abrangente, direcionada contra um dos pressupostos centrais de toda a teoria do reconhecimento de Honneth, qual seja o aspecto evolutivo das relações sociais, que é tomado como pressuposto. Respondê-la iria requerer possivelmente um novo artigo.

15 Honneth, A., op. cit., p. 211.

16 Hegel, G.W.F., op. cit., p. 31

17 Honneth, A., op. cit., p. 29. 
A segunda crítica diz respeito ao locus da escola entre as esferas de reconhecimento apontados por Honneth. A escola não poderia ser palco para todos os processos de reconhecimento, logo a sua qualificação como "microcosmo" precisaria ser bem situada. Nesse aspecto, cabe lembrar que, para Honneth, há uma gradação em termos de abrangência entre as esferas onde essa luta acontece. A primeira esfera, a família, seria mais estreita do que a segunda, a sociedade civil, que, por sua vez, seria mais estreita do que a terceira, o Estado. O primeiro processo de reconhecimento seria experimentado no espaço familiar, para depois migrar para um espaço mais amplo, a sociedade civil. Por fim, o reconhecimento seria experimentado no espaço mais amplo de todos, o Estado. Não haveria fundamento em afirmar que aquilo que cabe na família, na sociedade civil e no Estado caberia ipso facto no "microcosmo" da escola. Qual seria, então, o lugar da escola nesse processo?

Hannah Arendt, ${ }^{18}$ no ensaio A crise da Educação, oferece um possível caminho para responder a essa questão. Para Arendt, a crise contemporânea na educação é indissociável da crise política da modernidade, que por sua vez resulta da própria condição humana, tema central da sua reflexão filosófica. Arendt considera que "a infância é uma etapa temporária, uma preparação para a condição adulta", ${ }^{19}$ portanto uma preparação para o mundo. E o mundo, por sua vez, precisa ser entendido como construção tipicamente humana. Arendt não se refere ao mundo da natureza nem ao ambiente material, mas ao mundo cultural, institucionalizado, artificialmente criado, no qual o ser humano estabelece agenciamentos cognitivos e desenvolve relações nas diferentes esferas da vida. Nas palavras de Arendt, o mundo é onde o ser humano desenvolve sua "vita activa". ${ }^{20}$

A escola, na compreensão arendtiana, ${ }^{21}$ serviria como uma ponte, uma transição da família para o mundo. Ainda não é o mundo, mas uma preparação para ele. Se fôssemos expressar a visão de Hannah Arendt na terminologia de Axel Honneth, diríamos que a escola não se situaria nos espaços mais amplos da sociedade civil e do Estado, mas seria uma etapa prévia de transição entre o espaço familiar e aqueles. Para a vida em sociedade, a escola

18 Arendt, H. Entre o Passado e o Futuro. 8. ed. São Paulo: Perspectiva, 2016. p. 257-289.

19 Ibidem, p. 272.

20 Arendt, H. A Condição Humana. 10ª Ed. São Paulo/Rio de Janeiro: Ed. Forense Universitária, 2007. p. 15 et seq.

21 Arendt, H., op. cit. (2016), p. 278-279. 
não seria um ambiente político, apenas pré-político. Assim sendo, não poderia situar-se nem nos estreitos limites do espaço privado, domiciliar, nem na amplitude do espaço público, mas entre eles, de algum modo sobrepondo-se a ambos, sem, no entanto, neles diluir-se.

Nesse espaço transicional, a escola desenvolve sua função precípua de preservar a singularidade da criança, ou seja, o fato de que cada criança é um acontecimento único. A preservação da singularidade é necessária, prossegue Arendt, porque é justamente essa singularidade que permitirá à criança, mais adiante, renovar o mundo. E essa renovação, geração após geração, é o que permite que o mundo construído pela condição humana não morra. Escola, portanto, é também "conservação", 22 não no sentido de conservadorismo, mas no sentido de que, ao contribuir para manter a singularidade da criança, ela conserva e assegura a continuidade do mundo, mediante sua contínua transformação. ${ }^{23}$

Conforme indicado na introdução, uma das premissas desse ensaio é a de que a educação deve ser considerada como algo pelo qual alguém se torna o que é, numa perspectiva que favorece uma educação integral, voltada para o exercício pleno da cidadania. Nessas condições, para os fins aqui propostos, considera-se a escola como uma espécie de "laboratório social", onde seria possível ensaiar as relações de reconhecimento que ocorrem nas esferas sociais apontadas por Honneth, como parte do processo formativo, em preparação à vida adulta. ${ }^{24}$

As experiências de reconhecimento que ocorrem no ambiente escolar espelhariam, em fase preparatória, as três fases de reconhecimento honnethianas: o reconhecimento afetivo, potencialmente nos primeiros anos do ensino fundamental; mais adiante, o jurídico, no que tange à educação para o exercício dos direitos e deveres de cidadão e a formação de consciência sobre suas possíveis violações; e, finalmente, o solidário, que se manifestaria na própria interação social e na formação de vínculos pelo reconhecimento oriundo do(s) grupo(s) que o educando integra mesmo fora de sala de aula, considerando o ambiente escolar estendido.

22 Ibidem, p. 283.

23 César, M.R. de A.; Duarte, A. Hannah Arendt: Pensar a Crise da Educação no Mundo Contemporâneo. Educação e Pesquisa, v. 36, n.3, p. 823-837. São Paulo, set./dez. 2010. p. 826.

24 A presente análise parte da premissa já elaborada por Flickinger de que "o reconhecimento social providenciaria a condição para o desenvolvimento da autoestima do indivíduo no convívio com seu ambiente social" e que a "valorização [desse reconhecimento] é considerada a base da autonomia pessoal”. Flickinger, op. cit. (2011), p. 11. 
A busca pela afirmação da autoconfiança do educando tende a refletir, no relacionamento com seus pares, o processo de luta pelo reconhecimento como sujeito digno de afeto e atenção que provém das relações familiares. Tais relações são, segundo Honneth, sempre conflituosas, porque implicam a progressiva separação e individuação do sujeito em relação ao mundo que o cerca, no seio da família. A luta por reconhecimento no nível afetivo é transplantada da família para a escola desde o nível pré-escolar e fundamental, quando se tem início a interação do educando no meio social escolar. Os conflitos advindos do não-reconhecimento nesse nível primário de relações sociais afetam a construção da autoconfiança do indivíduo como sujeito capaz de interagir nesse meio. As violações, maus-tratos ou ameaças sofridas nessa fase inicial do processo educacional, quer ocorram no ambiente familiar, quer no escolar, terão efeitos deletérios para a afirmação da autoconfiança do educando, com potencial de persistir e manifestar-se ao longo de toda a vida social. Saavedra e Sobottka ${ }^{25}$ lembram que, para Honneth, o nível do reconhecimento do amor é o núcleo fundamental de toda a moralidade, afetando portanto não só o desenvolvimento do autorrespeito, mas também "a base de autonomia necessária para a participação na vida pública".

Se aplicarmos aqui as relações de reconhecimento, conforme descritas no início desta seção, teremos uma situação em que as resistências, reações e dificuldades de relacionamento e de integração na escola, muitas vezes com episódios de violência ou ameaça física, podem evidenciar uma luta por reconhecimento que impele o educando a recusar a atribuição de subjetividade ao outro, como modo de afirmação da própria subjetividade, ${ }^{26}$ ou que o conduz a uma situação de passividade diante do agressor, num instinto de aceitação da sua inferioridade como sujeito. Nessas circunstâncias, a ausência de uma pedagogia orientada à superação desse estado de coisas tenderá a protelar o enfrentamento de uma questão essencial na formação da subjetividade, derivada do não-reconhecimento de uma relação emotiva que tem origem no ambiente familiar e que resultará na falta de autoconfiança do educando, com reflexos que podem persistir ao longo de toda a sua vida social, com potenciais matizes patológicos.

A escola, como primeiro ambiente de socialização fora do círculo familiar, irá também favorecer o surgimento prático do segundo nível de luta

25 Saavedra e Sobottka, op. cit., p. 11.

26 Essa linha de análise poderia também oferecer uma melhor compreensão do fenômeno do "bullying" na escola. Foge ao escopo do presente texto, porém, aprofundar-se no tema. 
por reconhecimento apontado por Honneth, relativo à formação da moral social que deriva do respeito cognitivo resultante da atribuição de direitos subjetivos resguardados em lei. Como dito anteriormente, a privação desses direitos impede a formação de outro aspecto fundamental para o exercício da cidadania, qual seja o autorrespeito. Por exemplo, a não-observância de normas estabelecidas pela escola para orientar o comportamento dos educandos, ou a seletividade na aplicação dessas, por parte dos educadores, tende a reproduzir o fenômeno social do "apadrinhamento", tão comum no processo da formação social brasileira, o qual poderá ter como consequência a consolidação de uma situação subjetiva de baixo autorrespeito por parte daqueles que se sentirem afetados. Parece haver, aqui, um papel fundamental do educador em promover e consolidar a integridade social dos sujeitos envolvidos, a qual estaria ameaçada pelo conflito latente que resulta do desrespeito à subjetividade do educando. Nesse nível, afigura-se importante aplicar uma pedagogia voltada à criação de aptidões para o exercício de direitos e a identificação de responsabilidades e limites, com vistas a assegurar o reconhecimento recíproco.

No terceiro nível de reconhecimento, como visto, opera-se e consolida-se a formação de valores comuns que servirão de alicerce à estima social. Como lembram Saavedra e Sobottka, ${ }^{27}$ é nesse nível que se encontram os valores e os objetivos que funcionam como "um sistema de referência para a avaliação moral das propriedades pessoais dos seres humanos e cuja totalidade constitui a autocompreensão cultural de uma sociedade". Essa esfera de reconhecimento estaria tão fortemente vinculada à vida em comunidade, que não haveria outro modo de avaliar moralmente a capacidade e o desempenho dos membros da comunidade senão intersubjetivamente. Uma formação axiológica defectiva, nessa fase, afeta a autoestima do educando, que tende a sentir-se menosprezado, ofendido, desprestigiado e mesmo indigno de pertencer a determinada comunidade de valores materializados na figura do Estado.

Abre-se aqui, no nosso entendimento, uma justificativa suficiente para considerar a escola como espaço privilegiado e adequado para que certas experiências sejam possíveis, ainda que restritas ao nível formativo. É essa justificativa que permitirá, como mostraremos a seguir, fundamentar a importância do ensino da filosofia, particularmente no ensino médio. Trata-se, nas palavras de Flickinger, ${ }^{28}$ de atribuir à educação e seus agentes o desafio de

27 Saavedra e Sobottka, op. cit., p. 13.

28 Flickinger, H., op. cit. (2011), p. 11. 
apoiar os educandos em seus respectivos processos de desenvolvimento de uma "postura de reconhecimento social, através da qual ele mesmo consegue conquistar sua autoestima e autonomia individual".

Se a educação tem algum papel a desempenhar na criação e no fortalecimento da autonomia individual e na plena inserção do indivíduo no processo histórico-evolutivo que necessariamente integra, parece incontornável que o processo educacional deva considerar a luta por reconhecimento como uma experiência central para oferecer os meios de superação de conflitos e de construção de uma vida cidadã, ou seja, dotada de liberdade, orientada à autorrealização e integrada ao propósito de contribuir para o projeto humano, de modo justo e solidário.

\section{Fundamentações filosóficas para o ensino de filosofia no ensino médio}

A educação, entendida como a experiência de tornar-se quem se é, afigura-se como central ao processo de formação da subjetividade e da identidade. Uma educação voltada para a cidadania poderá ter melhores resultados se buscar promover o reconhecimento recíproco, mediante a criação de ambiente social que fomente a autoconfiança, o autorrespeito e a autoestima, como condições para a formação cidadã. A ausência de atenção pedagógica aos processos de luta por reconhecimento que emergem da interação social ao longo do processo educacional pode criar, como alerta Flickinger, ${ }^{29}$ um perigoso sistema de "desresponsabilização institucionalizada" na educação, oriundo do conflito entre diferentes diretrizes ético-morais que competem entre si e permitem que cada ator do sistema (educandos, professores, gestores escolares, instituições mantenedoras) aja de modo desconectado de um projeto pedagógico fundado em valores e objetivos comuns. Segundo Flickinger:

a insistência na suposta objetividade do conhecimento, a falta de vínculos com as experiências cotidianas dos alunos, ou o crescimento indiferenciado do ensino à distância, dificultam e até inibem a concreta experiência social, à base da qual se constrói o espaço pedagógico. ${ }^{30}$

29 Flickinger, H., op. cit. (2012), p. 229.

30 FLICKINGER, A teoria do reconhecimento na práxis pedagógica, 2012, p. 229 
A Base Nacional Comum Curricular (BNCC) na área de ciências humanas dispõe que, no ensino médio, se enfatizem as aprendizagens relativas ao "desafio de dialogar com o Outro" 31 . No mesmo capítulo, a BNCC reconhece que "é simples enunciar a diferença. Complexo é explicar a 'lógica' que produz a diversidade". ${ }^{32}$ Segundo a BNCC, o aprendizado, em ciências humanas, está relacionado com o reconhecimento de diferenças: "o estudo dessas categorias deve possibilitar aos estudantes (...) mobilizar a curiosidade investigativa sobre o seu lugar no mundo, possibilitando a sua transformação e a do lugar em que vivem, enunciar aproximações e reconhecer diferenças" 33 (grifo nosso).

O ensino de filosofia apresenta-se, aqui, como locus curricular privilegiado para amparar e dar sustentação a uma educação que objetive, em essência, o reconhecimento das diferenças pela via da ampliação das relações recíprocas de reconhecimento. Em apoio a essa tese, cabe lembrar que Hegel supunha que o reconhecimento recíproco é um pressuposto para o exercício da liberdade. Para Hegel, ${ }^{34}$ "sem reconhecimento não há liberdade e sem liberdade não se estabelece qualquer relação de reconhecimento". O reconhecimento do outro e de si mesmo é, portanto, essencial ao processo de construção de uma consciência individual de liberdade, com reflexos na vida social. Como o educando só conquista a autoconsciência na relação com o outro, a plenitude das relações sociais depende de uma educação que enfrente, decididamente, o déficit de reconhecimento, nos três níveis apontados por Honneth.

Em particular, a terceira fase da luta por reconhecimento, relativa à construção da autoestima, tende a consolidar-se num período mais avançado da educação básica, mais especificamente no ensino médio, em idade via de regra da adolescência, quando a luta por reconhecimento se mede pela capacidade de adquirir prestígio social junto aos colegas da escola. Nessa etapa da vida, não seria de esperar que a consciência de si já tenha incorporado a noção de Estado como referência de valores comuns, em cujo contexto ocorre, segundo Honneth, uma luta por reconhecimento centrada no aspecto da solidariedade. Esta, quando surge na etapa formativa, em ambiente

31 Brasil. Ministério da Educação. Base Nacional Comum Curricular. Brasília: MEC, 2018. p. 562.

32 Ibidem, p. 563.

33 Ibidem, p. 565.

34 apud Flickinger, H., op. cit. (2012), p. 222. 
escolar, pode manifestar-se nas relações com uma comunidade de valores mais imediata, criada informalmente pelos vínculos sociais com as pessoas de interação mais próxima.

Como a gramática do reconhecimento, conforme apresentada por Honneth, é essencialmente conflituosa, a luta pelo prestígio social requer a não-atribuição de subjetividade a quem se comportar de modo diferente ou fora dos padrões aceitos por esse grupo de relações mais imediatas. A manifestação do prestígio, nessa fase, pode ser buscada de várias maneiras, por exemplo: na ostentação consumista e na aderência a marcas e estilos diferenciados; na ousadia em desafiar a autoridade do professor; na impetuosidade em cortejar ou, adversamente, querer humilhar colegas; na transgressão em recorrer à recreação pelo uso de drogas, álcool ou cigarro; entre outras atitudes. Mesmo as que possam ser condenáveis num contexto que extrapole o grupo social específico criado em torno dessas referências, essas atitudes acabam concorrendo para formar uma comunidade de valores própria do ambiente escolar e partilhada por todos aqueles que sentem a necessidade de autoafirmar-se diante do grupo e ser por ele reconhecido. Se introduzirmos aqui o aspecto socioeconômico que afeta estudantes especialmente nas periferias e áreas vulneráveis, veremos que muitas vezes a luta pela própria sobrevivência impõe aos educandos a adoção de formas de vida social alheias a quaisquer expectativas de "normalidade", contribuindo para a formação de uma comunidade de valores distante do que propõe o ensino formal na escola.

Essa realidade pode ser aproveitada, no contexto pedagógico, como uma oportunidade para orientar o ensino de filosofia ao estudo e à vivência do conceito de reconhecimento da diferença. Tal orientação está em linha com a BNCC: no que se refere ao aprendizado sobre ética no ensino médio, a BNCC propõe que os estudantes sejam orientados a dialogar sobre os conceitos de respeito, convivência e bem comum em situações concretas, com estímulo ao acolhimento das diferenças, "tendo em vista a promoção do convívio social e o respeito universal às pessoas, ao bem público e à coletividade". 35

Não se trata, aqui, de querer forçar uma homogeneização social. Como aponta Flickinger, ${ }^{36}$ Honneth quer abrir espaço à diversidade cultural, às diferenças de opções e projetos de vida e à multiplicidade de convicções

35 Brasil. Ministério da Educação, op. cit., p. 567.

36 Flickinger, H., op. cit. (2012), p. 224. 
ideológicas. Patrícia Mattos, ${ }^{37}$ ao comentar os remédios propostos por Nancy Fraser para tentar corrigir as injustiças de uma ordem social desigual, ainda que não tenha tratado especificamente do âmbito pedagógico, antecipa a necessidade de alguma mudança cultural, voltada à:

[...] reavaliação positiva de identidades discriminadas e estereotipadas [...], valorização da diversidade cultural, ou ainda, a desconstrução e transformação dos padrões sociais de representação, interpretação e comunicação para permitir uma maior possibilidade de auto-interpretação para os membros da comunidade política. ${ }^{38}$

O conceito de reconhecimento, tal como proposto por Honneth, ao ir além da busca da autonomia e ao não se contentar com a ficção de igualdade de todos perante a lei, abre espaço para incorporar e reconhecer as diferenças no processo de construção de relações sociais mais solidárias, em linha com o desiderato previsto na BNCC. ${ }^{39}$ No contexto de uma sociedade como a brasileira, que se caracteriza pela diversidade étnica, cultural, social e econômica, pode-se afirmar que a teoria da luta por reconhecimento oferece um instrumental importante para ampliar projetos e oportunidades de vida e dar "voz também àquelas opções que fogem da normalidade niveladora". ${ }^{40}$

Por outro lado, não se deve ingenuamente supor que a teoria da luta por reconhecimento sirva de "contraponto ao individualismo contemporâneo" nem de apanágio moral de uma "liberdade cooperativa", como escreve Maurício R. Martins. ${ }^{41}$ Compreender a teoria honnethiana é um passo importante para a tomada de consciência crítica a respeito dos processos de lutas e conflitos sociais que definem e delimitam a autonomia do indivíduo. No entanto, por si só, essa teoria não visa superar, do ponto de vista moral, o individualismo como valor central das sociedades contemporâneas, em favor de algum modelo cooperativo e solidário que se afigure superior. Se é na in-

37 Mattos, P. O reconhecimento, entre a justiça e a identidade. Lua Nova, v. 63, p. 143-161, 2004, p. 146.

38 MATTOS, O reconhecimento, entre a justiça e a identidade 2004, p. 146.

39 Brasil. Ministério da Educação, op. cit., p. 562 et seq.

40 Mattos, P., op. cit., p. 146.

41 Martins, M. R. Teoria do Reconhecimento de Axel Honneth e Educação: observações introdutórias. Interfaces: Educação e Sociedade, n. 2, 2014. p. 43. 
tersubjetividade que se realiza a autonomia e o reconhecimento, é também no próprio grupo social onde residem os conflitos que uma teoria de base iluminista como a de Honneth não prescinde para justificar, em bases hegelianas, a própria autonomia e afirmação do eu.

Ciente dos limites na aplicação da teoria do reconhecimento, mas conhecedor também do potencial de afirmação dos valores do indivíduo na sociedade, o docente em filosofia poderá assim assumir papel mais relevante no processo educativo. Para tal, terá de trabalhar a problematização e a contextualização de questões enfrentadas pelos educandos, nos três níveis de reconhecimento apontados por Honneth. Esse entendimento, que como visto acima está alinhado com as diretrizes da BNCC, implica atribuir primazia ao reconhecimento sobre o conhecimento, nas palavras de Claudio Almir Dalbosco, ${ }^{42}$ "assegurando que a formação do vínculo emocional-afetivo esteja na origem da capacidade cognitiva". Em lugar de uma abordagem conteudista da disciplina, centrada na transmissão de conteúdos histórico-filosóficos, os educadores podem apoiar a formação da subjetividade pela aplicação, no processo pedagógico, das questões afetas ao reconhecimento. Trata-se talvez da mais importante contribuição que a filosofia no ensino médio tem a oferecer para a formação cidadã.

Uma abordagem pedagógica que privilegie a transmissão de conteúdos sobre a história da filosofia não será adequada nem suficiente para criar as oportunidades de expansão criativa e problematização de situações que explicitem os conflitos originados do não-reconhecimento nas três fases teorizadas por Honneth. A mera apresentação teórica da gramática dos conflitos sociais tampouco conduziria o educando a uma experiência filosófica singular. O educador terá seguramente diversos caminhos a escolher caso queira conduzir o aprendizado filosófico rumo à almejada ampliação das relações de reconhecimento. Vários filósofos, de diferentes correntes, poderão oferecer pontos de entrada para essa linha de pedagogia social, que demanda sobretudo reflexão sobre a própria experiência. Foge ao escopo do presente artigo oferecer um inventário de possibilidades didáticas para esse fim.

Entendemos que ficou assentada a relevância da teoria de Axel Honneth para fundamentar uma pedagogia social voltada para a educação cidadã, em resposta à indagação inicial do presente estudo. Ficou também justificado o papel da filosofia, em particular no ensino médio, como sendo instrumental

42 Dalbosco, C. A. Reificação, Reconhecimento e Educação. Revista Brasileira de Educação, v. 16, n. 46, 2011. p. 44. 
para favorecer a ampliação das relações de reconhecimento recíproco entre os educandos. Considera-se suficiente, em resposta às questões aqui propostas, o caminho aqui oferecido, com base a teoria do reconhecimento de Axel Honneth, como fundamentação filosófica que reforce a importância de integrar, no ensino de filosofia para a formação cidadã, uma práxis pedagógica orientada à superação dos conflitos resultantes da luta por reconhecimento, e possa dar sustentação a uma educação voltada para a formação cidadã.

Conforme exposto ao longo deste artigo, parece ter-se evidenciado que a teoria de Axel Honneth sobre a luta por reconhecimento oferece uma base sólida e útil a uma pedagogia social orientada à construção da cidadania. O ensino de filosofia, caso incorpore o instrumental proposto por Honneth acerca dos três níveis de reconhecimento, pode fortalecer o processo educacional voltado para a formação cidadã, por meio de uma mudança cultural orientada por uma ética de respeito à diversidade e de reforço da autonomia do indivíduo e da autoestima social, o que contribuirá, acreditamos, à autorrealização pessoal numa comunidade de valores construída coletivamente por sujeitos "conscientes de si". Esse propósito está alinhado com a BNCC.

A teoria de Honneth afigura-se, enfim, um caminho promissor para o filósofo da educação e para o docente em filosofia, por oferecer uma oportunidade de balizar o aprendizado de filosofia na fixação de uma comunidade de valores aberta, inclusiva, fundada no respeito às diferenças e às minorias e na facilitação das relações sociais, com vistas a fortalecer nos educandos a autoconfiança, o autorrespeito e a autoestima. 


\section{Referências}

ARENDT, H. A Condição Humana. 10ª . Ed. São Paulo/Rio de Janeiro: Ed. Forense Universitária, 2007. 352 p.

Entre o Passado e o Futuro. Trad. Barbosa, M. São Paulo: Perspectiva, 2016. $436 \mathrm{p}$.

BRASIL. Ministério da Educação. Base Nacional Comum Curricular. Brasília: MEC, 2018.

Disponível em: < http://basenacionalcomum.mec.gov.br/ >. Acesso em: 2 jul 2019.

CÉSAR, M.R. de A.; DUARTE, A. Hannah Arendt: Pensar a Crise da Educação no Mundo Contemporâneo. Educação e Pesquisa, v. 36, n. 3, p. 823-837. São Paulo, set./ dez. 2010.

DALBOSCO, C. A. Reificação, Reconhecimento e Educação. Revista Brasileira de Educação, v. 16, n. 46, 2011. p. 33-49.

FLICKINGER, H. Autonomia e reconhecimento: dois conceitos-chave na formação. Educação, v. 34, n. 1. 2011. Disponível em: <http://revistaseletronicas.pucrs.br/ojs/ index.php/faced/article/view/8663>. Acesso em: 2 jul 2019.

A teoria do reconhecimento na práxis pedagógica: a exemplo de conflitos entre diretrizes ético-morais. Revista Espaço Pedagógico, v. 18, n. 2, 2012. Disponível em: <http://www.seer.upf.br/index.php/rep/article/view/2424>. Acesso em: 21 nov. 2018.

HEGEL, G.W.F. Fenomenologia do Espírito. 2 ed. Petrópolis: Vozes, 2003. 549 p.

HONNETH, A. Luta por reconhecimento: a gramática dos conflitos sociais. 2. ed. São Paulo: Editora 34, 2009. 291 p.

KOJÈVE, A. Introdução à leitura de Hegel. Trad. Estela dos Santos Abreu. Rio de Janeiro: Contraponto, 2002. 557 p.

MARTINS, M. R. Teoria do Reconhecimento de Axel Honneth e Educação: observações introdutórias. Interfaces: Educação e Sociedade, n. 2, 2014. p. 35-47. Disponível em: < http://local.cnecsan.edu.br/revista/index.php/pedagogia/article/view/25>. Acesso em: 2 jul 2019.

MATTOS, P. O reconhecimento, entre a justiça e a identidade. Lua Nova, v. 63, p. 143-161, 2004.

SAAVEDRA, G. A.; SOBOTTKA, E. A. Introdução à teoria do reconhecimento de Axel Honneth. Civitas - Revista de Ciências Sociais, 2008, v. 8, n. 1 (jan.-abr.). Disponível em: <http://www.redalyc.org/articulo.oa?id=74211531002>. Acesso em: 31 out. 2018. 